Rozprawy Komisji Językowej ŁTN, t. LXVII, 2019

ISSN 0076-0390; e-ISSN 2450-9310

https://doi.org/10.26485/RKJ/2019/67/6

Beata Gala-Milczarek*

(1D) https://orcid.org/0000-0001-7411-7568

\title{
ZJAWISKO WARIANTYWNOŚCI MOTYWACYJNEJ \\ W KATEGORYZACJI RZECZOWNIKOWYCH DERYWATÓW GWAROWYCH
}

\author{
THE PHENOMENON OF MOTIVATIONAL VARIABILITY \\ IN THE CATEGORIZATION OF DIALECTAL \\ SUBSTANTIVAL DERIVATIVES
}

\begin{abstract}
The domain of discourse concerns the phenomenon of the variant participation of the word-formation base forms in the process of categorizing the northern Lesser Poland dialects functioning in the vocabulary and adjacent noun formations of a functional nature. The principle of in/chronicity adopted in the description allowed the creation of formations which, categorized within the semantic classes having primary relations with verb base forms, are also connected with the variant participle or noun base forms.
\end{abstract}

Keywords: dialectology, dialectal word formation, nouns

Słowa kluczowe: dialektologia, słowotwórstwo gwarowe, rzeczowniki

Zagadnienie wariantywności motywacyjnej w procesie kategoryzacji derywatów rzeczownikowych zostanie przedstawione na podstawie materiału gwarowego wyselekcjonowanego z leksyki zgromadzonej i usystematyzowanej w Stownictwie ludowym z terenu byłych województw kieleckiego i łódzkiego prof. Karola Dejny [1974-1985]. Zjawisko to dostrzeżono w toku rozważań nad czynnościowym charakterem derywatów rzeczownikowych w gwarach północnomałopolskich i przyległych. Celem podjętych w tym temacie rozważań było określenie specyfiki relacji między jednostkami derywowanymi - właściwymi i sekundarnymi -

* Uniwersytet Łódzki, Wydział Filologiczny, Zakład Dydaktyki Języka i Literatury Polskiej, ul. Pomorska 171/173, 90-236 Łódź; e-mail: 601354532@orange.pl. 
dewerbatywami a znaczeniami czynności bezpośrednio i pośrednio je motywujących. Przyjęta w opisie zasada chronii pozwoliła na wyłonienie formacji, które - kategoryzowane w obrębie klas semantycznych o prymarnych relacjach z podstawami czasownikowymi - wykazują także powiązania z podstawami wariantywnymi, głównie imiesłowowymi i rzeczownikowymi. Ujęcie in/chroniczne jest odpowiedzią na obserwowaną w ostatnich latach wyraźną tendencję do zacierania się ostrości opozycyjnej między podejściem synchronicznym a diachronicznym. In/chronia jako metoda interpretacji słowotwórczej formacji derywowanych daje bowiem możliwość łączenia tych dwóch stanowisk.

Jak pisał Sławomir Gala:

Diachronia i synchronia [...] to dwie wzajemnie się uzupełniające metody, z których pierwszą interesuje geneza i ewolucja struktury słowotwórczej, drugą - funkcja derywatu względem innych derywatów [Gala, 2011, s. 58; por. Nagórko, 1998, s. 165].

Jest to odejście - jak się wydaje - od stereotypu, zasady wyłącznie synchronicznej albo diachronicznej [Grochola-Szczepanek, 2002, s. 23; Waszakowa, 2004, s. 67-80; Kleszczowa, 2005, s. 253-290; Gala, 2006, s. 82; 2009, s. 52]. Biorąc pod uwagę fakt, że interpretacji słowotwórczej zostało poddane słownictwo gromadzone w drugiej połowie XX wieku i funkcjonujące w mowie informatorów urodzonych na przełomie wieków, należy przyjąć, że niejednokrotnie jego struktura morfologiczna jest nośnikiem cech archaicznych o trudnej do ustalenia dolnej granicy chronologicznej. Funkcja i charakter derywatów, eksponowane na gruncie słowotwórstwa synchronicznego, w materiale północnomałopolskim są zaś możliwe do wydobycia i zdefiniowania z przytoczeń gwarowych bądź też podstaw wskazanych $\mathrm{w}$ obrębie zgromadzonego materiału leksykalnego. Dane lokalizowane w tej przestrzeni historycznej, poddawane interpretacji słowotwórczej, skłaniają do niwelowania opozycji podejścia synchronicznego czy diachronicznego i przyjęcia chronii jako właściwej zasady interpretacyjnej. Ta bowiem - jak ujął to S. Gala:

[...] nie ogranicza cezury chronologicznej danych, nie stawia na przeciwstawnych biegunach synchronii i diachronii, wydaje się przydatna w definiowaniu słowotwórstwa gwarowego ustalonego w różnych cezurach chronologicznych. Przyjmując in/chronię jako zasadę interpretacyjna, odsłaniamy formacje $\mathrm{z}$ [ich] prymarną funkcją kategorialną. Proponowana perspektywa może prowadzić do wielu rekonstrukcji stanu pierwotnego derywatów, co służy odtworzeniu z miarę reprezentatywnego stanu słowotwórstwa paradygmatycznego - gramatycznego, opartego na prymarnych relacjach między odpowiednią klasą gramatyczną wyrazów podstawowych a wyrazami pochodnymi i wykładnikami derywacyjnymi [Gala, 2011, s. 62; por. Gala, Gala-Milczarek, 2014]. 
Przyjęcie in/chronii jako zasady interpretacji słowotwórczej derywatów doprowadziło do wyłonienia i opisu formacji określanych z perspektywy słowotwórstwa synchronicznego mianem derywatów semantycznych czy właściwych, tzn. takich, które zachowują ścisły związek semantyczny z podstawą [por. Grzegorczykowa, Puzynina, 1979, s. 21; Grzegorczykowa, 1998, s. 370-372], i onomazjologicznych, czyli takich, które z podstawami wchodzą jedynie w asocjacyjne związki semantyczne [por. Nagórko-Kufel, 1975; Grzegorczykowa, 1998, s. 362, 370-372].

I kwestia najistotniejsza - przyjęcie zasady chronii daje możliwość wskazania w strukturach odczasownikowych o wykładnikach: -(ił)ka, -(an)ka, -(on)ka, -(it)ka itp., szczególnie w kategorii nazw rezultatów czynności, także ogniw (taktów) derywacji imiesłowowej, por. zgniłka $\leftarrow$ zgniły $\leftarrow$ zgnić, krajanka $\leftarrow$ krajany $\leftarrow$ krajać, trzęsionka $\leftarrow$ trzęsiony $\leftarrow$ trzaśśc, odbitka $\leftarrow$ odbity $\leftarrow$ odbić. Jak wykazano w opisie rzeczowników gwarowych, przyjęcie wariantywnych interpretacyjnie podstaw nie decydowało o zmianie funkcji derywatów, zachowując ich semantyczne powiązania ze znaczeniami czynności [por. m.in. Dokulil, 1979, s. 149; Janowska, 2007, s. 28-29].

Ponadto zjawisko wariantywności motywacyjnej dostrzeżono w formacjach o paralelnych podstawach czasownikowo-rzeczownikowych w derywatach typu: handlowiec: handlować // handel, druciarz: drutować // drut, lamentnik: lamentować // lament.

W wyniku analizy słowotwórczej derywatów o prymarnie wskazanej motywacji czasownikowej można nakreślić pewne prawidłowości w zakresie ustalania motywacji wariantywnych. Podstawy paralelne imiesłowowo-czasownikowe wykazano w obrębie trzech kategorii: nazw rezultatywnych, nazw obiektów i nazw lokatywnych. Podstawy rzeczownikowe funkcjonują obok czasownikowych głównie w kategorii nazw subiektów czynności, jedynie pojedyncze przykłady wskazano wśród nazw czynności czy nazw instrumentalnych. Zarówno w jednym, jak i w drugim przypadku podstawy paralelne są wynikiem historycznych procesów derywacyjnych, często uwzględnianych, z punktu widzenia słowotwórstwa funkcjonalnego, w strukturach peryfrastycznych. Wskazanie głównie form imiesłowowych typu: zgnity, kłosowany, przebierany, rwany, wysiedlony, orany, przeorany, przędziony, dzielony, lepiony, maszczony, trzęsiony, dziabany, krajany, lany, parowany, kruszony, obwarzony, przebierany, redlony, skubany, szczepiony, miądlony, sadzony, święcony, kochany, wychowany, dany, siekany, spalony, kopany, odbity czy podbity, struty jako podstaw paralelnych dla klas dewerbatywów prymarnych nie ma wpływu na wyrażane przez nie wartości, jest jedynie czynnikiem wprowadzającym modyfikacje w obszarze semantyki 
kategorialnej. Postrzegane obecnie jako przymiotniki, wnoszą do jednostek derywowanych atrybutywny odcień znaczeniowy, wskazują na ich właściwość, cechę charakterystyczną. I tak w obrębie formacji rezultatywnych, lokatywnych czy obiektowych wyraźnie można wyodrębnić podgrupy semantyczne wykazujące znaczeniowe i formalne powiązania z podstawami atrybutywnymi, por. nomina rezultativa: zgniłek 'siano, które zgniło' czy zgniłka 'zgniły owoc': zgnić / zgnity, obwarzanek 'rodzaj ciastka': obwarzyć / obwarzony, kruszonki (pl.t.) 'rodzaj klusek': kruszyć / kruszony, dziabanki (pl.t.) 'kopytka': dziabać / dziabany, krajanki (pl.t.) 'kluski' i krajanka 'pokrojone kartofle przygotowane do sadzenia': krajać / krajany, lanki 'zupa, którą się gotuje z mąki rozmąconej w mleku': lać / lany, parowanki 'kluski na parze gotowane': parować / parowany, przędzionko 'przędza zdjęta z motowidła' : przaśść, przęd- / przędziony, strutka 'kawałki mięsa lub chleba zatrute trucizną na szczury i myszy, wykładane dla trucia tych gryzoni': struć / struty, odbitka 'podskórne uszkodzenie na stopie, wywołane dłuższym chodzeniem': odbić / odbity, maszczonka 'jedzenie dla świń': maścić [Brückner, 1993, s. v. maść], 'krasić' [Karłowicz, Kryński, Niedźwiedzki, 1900-1927] / maszczony; trzęsionka 'jedzenie dla krów ze słomy i siana': trzassć / trzęsiony, dzielanka 'część pola, lasu': dzielić / dzielony, lepianka 'dom ulepiony z gliny': lepić / lepiony, przeoranica 'rów odwadniający': przeorać / przeorany, wysiedleniec: wysiedlić / wysiedlony, kłosowaniec 'snop z grubsza omłocony': kłosować 'młócić z grubsza' / klosowany, przebieraniec 'przebieraniec karnawałowy': przebierać (się) / przebierany, rwaniec 'kluska rwana': rwać / rwany; nomina locativa: oranka, oranisko 'pole zaorane': orać / orany, spalenisko 'pogorzelisko': spalić / spalony, kopanina 'karczowisko': kopać / kopany i nazwy obiektów: przerabianka 'materiał tkany z wełny na podstawie lnianym': przerabia / przerabiany, redlanka 'rządek kartofli': redlić / redlony, skubanka 'kartofel ugotowany w skórce': skubać / skubany, szczepianka 'szczep': szczepić / szczepiony.

Za przyjęciem podstaw czasownikowych jako nadrzędnych i decydujących w kategoryzacji wymienionych derywatów przemawia fakt funkcjonowania w leksyce gwarowej struktur wariantywnych ${ }^{1}$ o wyłącznej, jak ustalono, motywacji czasownikowej. Dotyczy to głównie nazw rezultatywnych, por. rwaniec/ rwanka / rwak: rwać, przeoranica / przeorka / przeorówka: przeorać, dzielanka /

1 Przez warianty słowotwórcze rozumie się struktury, które bazują na wspólnych podstawach derywacyjnych, różnią je jedynie wykładniki formalne kształtujące nazwy w ramach jednej wartości kategorialnej [Heinz, 1974; Sierociuk, 2006, s. 209], a ich wariantywność rozpatrywana jest w odniesieniu do zespołów gwarowych objętych eksploracją. Istotą wariancji jest bowiem zwielokrotnienie danej jednostki systemowej, która pojawia się w postaciach różnych, lecz ekwiwalentnych, jeśli chodzi o istotę owej jednostki [Heinz, 1974, s. 139; patrz: Pelcowa, 2001, s. 74-82; Marciniak-Firadza, 2012; Gala, 2014; Gala-Milczarek, 2016, s. 24, 326]. 
dziat: dzielić, trzęsionka / trzaska 'galareta z wygotowanych kości': trzaśśc, odbitka / odbitek / odbit: odbić, przędzionko / przędza: prząść, przęd-. Uznać zatem należy, że z punktu widzenia semantyki kategorialnej włączenie form imiesłowowych w relacje motywacyjne służy jedynie modyfikacji ich znaczeń. Jednak w perspektywie typologicznej ich obecność odsłania złożoność wykładników formalnych typu: -(ani)ec, -(eni)ec, -(an)ica, -(it)ka, -(an)ka, -(on)ka, -(it)ka, -(ut)ka, -(on)ko, -(an)ki (pl.t.), -(on)ki (pl.t.), -(it)ek, -(an)ek, -(eni)ak, -(an)ina czy -(eni)sko.

Jak ustalono, derywaty dwumotywacyjne czasownikowo-rzeczownikowe w poddanej analizie leksyce gwarowej występują zdecydowanie rzadziej. Wskazano je głównie w obrębie wartości kategorialnej nazw subiektów czynności: druciarz: drutować / drut, murarz: murować / mur, luciarz: lutować / lut itp. Pojedyncze przykłady wyrażają także nazwy środków czynności, np. gwintownik: gwintować / gwint, szpuntownik: szpuntować / szpunt, śrutownik: śrutować / śruta czy miejsc, np. targowica: targować / targ. Ze względu na głównie dewerbalny charakter wymienionych kategorii omawiane derywaty są parafrazowane w relacjach ze znaczeniami czynności. Przyjąć jednak należy, że prymarne w ujęciu diachronicznym są dla nich podstawy rzeczownikowe, natomiast motywacje czasownikowe pojawiły się, gdy wykorzystane jako podstawy rzeczowniki posłużyły do utworzenia odpowiednich form czasownikowych głównie na -ować, a także na -ićl-yć. Jak pisze Henryk Wróbel:

Nie są one wyspecjalizowane w przekazywaniu określonych znaczeń predykatów, lecz są globalnymi zastępnikami czasowników o różnych treściach, a rodzaj relacji między nimi i podstawami jest dedukowany ze wszystkich składników struktury zdaniowej, opartej na derywacie. Na płaszczyźnie formalnej derywaty te odpowiadają połączeniu orzeczenia czasownikowego z dopełnieniem lub rzeczownikowym członem luźnym (tradycyjnym okolicznikiem, dlatego nazywane były formacjami dopełnieniowo-okolicznikowymi [por. Grzegorczykowa, 1969]). Jest to spostrzeżenie o tyle ważne, że niektóre derywaty wydają się automatycznymi ściągnięciami grupy orzeczenia z rzeczownikiem [Wróbel, 1998, s. 578].

Wśród wskazanych w materiale gwarowym czasowników motywacyjnych najbardziej reprezentatywną grupę stanowią formacje $\mathrm{z}$ wbudowanym wyrażeniem argumentu wytworu, środka czy obiektu czynności, por. murować - stawiać mur, murarz: to 'ten, kto muruje', 'stawia mury', drutować - zalepiać drutem, druciarz to 'ten, kto drutuje' bądź 'ten, kto drutem zalepia garnki', haftować - robić na czymś haft, hafciarz to 'ten, kto haftuje' bądź 'ten, kto wyszywa haft', lutować - robić na czymś lut, luciarz: 'ten, kto lutuje', 'ten, kto naprawia, np. garnki, robiąc na nich lut', szklić - szkło 'coś robić, tworzyć za pomocą szkła', szklarz: 'ten, kto szkli', 'wstawia szkło'. Wyrażone w strukturach czasowników motywacyjnych relacje znajdują przełożenie na charakter kategoryzacji ustalanych od 
nich derywatów rzeczownikowych. Traktowane jako dewerbatywa, włączane są do kategorii nazw subiektów czynności o równorzędnych motywacjach rzeczownikowych, modyfikujących funkcję semantycznokategorialną subiekta o treści wynikające z roli argumentów ujętych w strukturze podstaw, czyli wytworu, środka czy obiektu czynności. Stąd wynikają wartości kategorialne subiektów czynności definiowanych $\mathrm{w}$ relacjach desygnatu $\mathrm{z}$ wytworem podejmowanych przez niego czynności, narzędziem/materią, z którą czynność jest związana czy obiektem, który czynności jest poddawany.

W analogiczny schemat wpisują się derywaty instrumentalne, por. gwintownik: gwintować / gwint, szpuntownik: szpuntować / szpunt, śrutownik: śrutować / śruta. Definiowane kategorialnie w relacjach z motywującymi je czasownikami wpisują się w klasę dewerbatywów prymarnych. Uwzględnienie podstaw rzeczownikowych - historycznych zapożyczeń z języka niemieckiego, na podstawie których już na gruncie polskim powołano czasowniki - modyfikuje ich znaczenia słowotwórcze, wpisując je tym samym w obszar wartości kategorialnej nazw instrumentalnych powoływanych ze względu na - w ich przypadku - rezultat działania.

Pozostała jeszcze grupa derywatów motywowanych przez czasowniki powoływane na bazie podstaw rzeczownikowych o znaczeniach czynności typu: podróżować: podróż, a zatem podróżny to 'ten, kto podróżuje'i 'ten, kto jest w podróży', handlować: handel - handlarz to 'ten, kto handluje', a także 'ten, kto trudni się handlem', kolędować: kolęda - kolędziarz: 'kolęduje' i 'chodzi z kolędą', czarować: zajmować się czarami - czarownik: 'ten, kto czaruje', 'ten, kto rzuca czary', awanturować się: awantura - awanturnik to 'ten, kto się awanturuje' i 'ten, kto wszczyna awantury', lamentować: lament - lamentnik to 'ten, kto lamentuje', 'podnosi lament', psocić: psota - psotnik to 'ten, kto psoci' i 'ten, kto czyni psoty', figlować: figiel - figlarz to 'ten, kto figluje i 'ten, kto innym robi figle', kantować: kant-kanciarz to 'ten, kto kantuje (oszukuje)' i 'ten, kto robi kanty, oszustwa', plotkować: plotka-plotkarz / plotuch / pleciuga to 'ten, kto plotkuje' i 'człowiek, który rozpowiada plotki', pracować: praca - pracierz to 'ten, kto dużo pracuje' oraz 'ten, kto lubi pracę', grzeszyć: grzech - grzesznik to 'ten, kto grzeszy', 'ten, kto popełnia grzech' ale i ‘człowiek grzeszny'. Wskazane jako podstawowe dla derywatów rzeczownikowych czasowniki powołano w rezultacie transpozycji, czyli przekształceń wyłącznie formalnych. Nie są one zatem nośnikami dodatkowych treści. Ustalenie w obrębie derywatów rzeczownikowych podstaw paralelnych czasownikowo-rzeczownikowych jest w ich przypadku również zabiegiem wyłącznie formalnym. Powiązania z podstawami rzeczownikowymi nadają im wymiar nazw atrybutywnych, przy czym atrybut, właściwość wyraża się w skłonności do pewnych zachowań: awantur, lamentu, figli, psot, kantów 
'oszustw', plotek czy grzechu. Włączenie w układ motywacyjny w przypadku rzeczownika grzesznik także podstawy przymiotnikowej-grzeszny - bezspornie decyduje o jej atrybutywnym znaczeniu. Motywacje czasownikowe wprowadzają je natomiast w obszar wartości kategorialnej nazw subiektów, których działania mają wyraźnie nacechowany, naznaczony charakter, wnoszony przez znaczenia czynności atrybutywnych bądź dopełniany w peryfrazach, por. pracierz 'ten, kto dużo pracuje lub lubi pracować'. Neutralne, wyłącznie czynnościowe znaczenie subiekta zachowują formacje: podróżny, handlarz, kolędziarz czy czarownik.

Przedstawione zagadnienie wariantywności motywacyjnej omówione zostało na podstawie najbardziej reprezentatywnych przykładów rzeczowników pochodnych, kategoryzowanych w obrębie tzw. dewerbatywów prymarnych, czyli formacji, dla których verbum stanowi formalną podstawę procesu derywacyjnego. Przyjęte ujęcie in/chroniczne daje możliwość szerszego przedstawienia zjawisk derywacyjnych, uwzględnienia wszelkich relacji motywacyjnych oraz ukazania ich wpływu na kategoryzację jednostek derywowanych. Taka interpretacja formacji pochodnych służy odsłonięciu kolejnych etapów procesów derywacyjnych oraz, co wydaje się istotne z punktu widzenia słowotwórstwa typologicznego, objaśnia zjawisko kształtowania się sufiksów rozbudowanych jako wykładników wartości kategorialnych. Interpretacja derywatów prowadzona zgodnie z przyjętymi zasadami in/chronii daje możliwość śledzenia zmian w obrębie semantyki kategorialnej, uchwycenia modyfikacji w zakresie znaczeń słowotwórczych poszczególnych jednostek derywowanych na bazie podstaw wariantywnych. In/chronia nie stawia bowiem kategorycznej granicy przy wytyczaniu powiązań motywacyjnych derywatów i znaczeń dla nich podstawowych.

\section{BIBLIOGRAFIA}

BRÜCKNER Aleksander, 1993, Stownik etymologiczny języka polskiego, Wiedza Powszechna, Warszawa.

Dejna Karol, 1974-1985, Stownictwo ludowe z terenu bylych województw kieleckiego i łódzkiego, „Rozprawy Komisji Językowej ŁTN”, t. XX, s. 189277, t. XXI, s. 135-290, t. XXII, s. 135-268, t. XXIII, s. 147-290, t. XXIV, s. 149-274, t. XXV, s. 123-276, t. XXVI, s. 117-257, t. XXVII, s. 129-281, t. XXVIII, s. 11-261, t. XXIX, s. 83-233, t. XXX, s. 91-265.

DokUlil Miloš, 1979, Teorie derywacji, Zakład Narodowy im. Ossolińskich, Wrocław-Warszawa-Kraków-Gdańsk.

Gala Sławomir, 2006, Diachronia czy synchronia w badaniach słowotwórstwa gwarowego, „Rozprawy Komisji Językowej ŁTN”, t. LI, s. 79-84. 
Gala Sławomir, 2009, W sprawie paradygmatycznego wymiaru słowotwórstwa gwarowego, „Rozprawy Komisji Językowej ŁTN”, t. LIV, s. 47-55.

Gala Sławomir, 2011, Chronia w stowotwórstwie gwarowym, „Rozprawy Komisji Językowej ŁTN", t. LVI, s. 57-64.

Gala Sławomir, 2014, W sprawie wariantywności stowotwórczej, w: B. Grochala, E. Pałuszyńska, red., Teksty, podteksty i konteksty. O współczesnej polszczyźnie i jej kontaktach z innymi językami stowiańskimi. Tom jubileuszowy dedykowany Profesor Bożenie Ostromęckiej-Fraczak, Wydawnictwo Uniwersytetu łódzkiego, Łódź, s. 87-95.

Gala Sławomir, Gala-Milczarek Beata, 2014, Rzeczownikowe derywaty sufiksalne $w$ gwarach pótnocnomałopolskich i małopolsko-mazowiecko-wielkopolskiego pogranicza, Łódzkie Towarzystwo Naukowe, Łódź.

Gala-Milczarek Beata, 2016, Czynnościowy charakter derywatów rzeczownikowych $w$ gwarach pótnocnomalopolskich i przyległych. Studium morfologiczno-leksykalne, Wydawnictwo Uniwersytetu Łódzkiego, Łódź.

Grochola-SzczepaneK Helena, 2002, Rzeczowniki złożone w gwarach polskich, Wydawnictwo Naukowe DWN, Kraków.

GrZEGORCZYKowa Renata, 1969, Czasowniki odimienne we współczesnym języku polskim, Zakład Narodowy im. Ossolińskich, Wrocław-Warszawa-Kraków. GrZegorczyKowa Renata, 1998, Gramatyka współczesnego języka polskiego. Morfologia, Wydawnictwo Naukowe PWN, Warszawa.

Grzegorczykowa Renata, Puzynina Jadwiga, 1979, Stowotwórstwo wspótczesnego języka polskiego, Państwowe Wydawnictwo Naukowe, Warszawa.

HeInz Adam, 1974, Pojęcie i rola wariantu językowego, „Biuletyn Polskiego Towarzystwa Językoznawczego", z. 32, s. 137-157.

JANOWSKA Aleksandra, 2007, O swoistości derywacji na tle innych sposobów nominacji, w: A. Achtelik, J. Tambor, red., Sztuka czy rzemiosło? Nauczyć Polski i polskiego, Wydawnictwo Gnome, Katowice, s. 28-34.

KarŁowicz Jan, KryŃski Adam, NiedźwiedzKi Władysław, red., 1900-1927, Stownikjęzyka polskiego, t. 1-8, Państwowy Instytut Wydawniczy, Warszawa. Kleszczowa Krystyna, 2005, Przemiany systemu stowotwórczego, w: S. Borawski, red., Rozprawy o historii języka polskiego, Wydawnictwo Uniwersytetu Zielonogórskiego, Zielona Góra, s. 253-290.

MARCINIAK-FIRADZA Renata, 2012, Wariantywność gwarowych formacji stowotwórczych na przykładzie nazw osobowych wykonawców czynności, „Rozprawy Komisji Językowej ŁTN", t. LVIII, s. 209-222.

NAGÓRKo Alicja, 1998, Zarys gramatyki polskiej (ze stowotwórstwem), Wydawnictwo Naukowe PWN, Warszawa. 
NAGóRKo-KufEL Alicja, 1975, O dwóch typach motywacji leksemów rzeczownikowych we współczesnej polszczyźnie, „Poradnik Językowy”, z. 10, s. 525-532. Pelcowa Halina, 2001, Interferencje leksykalne w gwarach Lubelszczyzny, Wydawnictwo Uniwersytetu Marii Curie-Skłodowskiej, Lublin.

Sierociuk Jerzy, 2006, Specyfika wariantywności stowotwórczej w gwarach, w: tegoż, red., Gwary dziś. 3. Wewnętrzne zróżnicowanie języka wsi, Wydawnictwo Poznańskiego Towarzystwa Przyjaciół Nauk, Poznań, s. 209-214. Waszakowa Krystyna, 2004, Stowotwórstwo a niektóre zalożenia kognitywizmu, „Poradnik Językowy”, z. 2, s. 67-80.

WróBel Henryk, 1998, Czasownik, w: R Grzegorczykowa, R. Laskowski, H. Wróbel, red., Gramatyka wspótczesnego języka polskiego. Morfologia, Wydawnictwo Naukowe PWN, Warszawa, s. 536-583.

\title{
Beata Gala-Milczarek
}

\section{ZJAWISKO WARIANTYWNOŚCI MOTYWACYJNEJ W KATEGORYZACJI RZECZOWNIKOWYCH DERYWATÓW GWAROWYCH}

\begin{abstract}
Streszczenie
Rozważania zawarte w artykule dotyczą zjawiska wariantywnego udziału podstaw słowotwórczych w procesie kategoryzacji funkcjonujących w leksyce gwar północnomałopolskich i przyległych formacji rzeczownikowych o charakterze czynnościowym. Przyjęta w opisie zasada in/chronii pozwoliła na wyłonienie derywatów, które - kategoryzowane w obrębie klas semantycznych o prymarnych relacjach z podstawami czasownikowymi - wykazują także powiązania z wariantywnymi podstawami imiesłowowymi czy rzeczownikowymi. Zaproponowane ujęcie daje możliwość szerszego przedstawienia zjawisk derywacyjnych w obrębie omawianych formacji, uchwycenia wszelkich możliwych dla nich relacji motywacyjnych oraz wykazania wpływu tych relacji na kształtowanie się funkcji kategorialnych jednostek pochodnych.
\end{abstract}

\section{THE PHENOMENON OF MOTIVATIONAL VARIABILITY IN THE CATEGORIZATION OF DIALECTAL SUBSTANTIVAL DERIVATIVES}

\section{Summary}

The domain of discourse concerns the phenomenon of the variant participation of the word-formation base forms in the process of categorizing the northern Lesser Poland dialects functioning in the vocabulary and adjacent noun formations of a functional nature. The principle of in/chronicity adopted in the description allowed the creation of formations which, categorized within the semantic classes having the primary relations with the verb base forms, are also connected with the variant participle or noun base forms. The proposed approach gives the opportunity to present 
more fully the derivational phenomena, to consider all the motivational relations and to show their impact on the categorization of derived units. Such an interpretation of derivative formations is intended to expose the next stages of derivative processes and, importantly in terms of typological word-formation, to form extended suffixes as expressions of categorical values. The interpretation of derivatives carried out in accordance with the accepted principles of in/chronicity provides the opportunity to follow changes within the categorical semantics, to capture modifications in the word-formation meanings of individual derived units on the basis of variant base forms because the in/chronicity does not set a categorical limit when determining relations between motivational derivatives and the meanings which are basic for them. 